\title{
O Libro de medicina, cirugía, e botica: um manuscrito anônimo de Matéria médica rioplatense da primeira metade do século XVIII
}

\author{
The Libro de medicina, cirugía, e botica: an anonymous manuscript of \\ Matéria médica from the Río de la Plata region from the first half of \\ the 18th century
}

\section{Eliane Cristina Deckmann Fleck ${ }^{1}$ \\ Franz Obermeier ${ }^{2}$}

RESUMO

Neste artigo, apresentamos uma análise preliminar do Libro de cirugía, de 1725, um manuscrito anônimo de medicina e farmácia, que se encontra na Biblioteca do convento da ordem franciscana de Catamarca, Argentina, e se mantém inédito até hoje. Sua transcrição e análise contribuem significativamente para a reconstituição da cultura científica vigente na América platina do Setecentos, principalmente, no que concerne aos saberes e às práticas medicinais que circulavam na região e eram empregados nas reduções jesuíticas. Além de discutirmos o título dado ao manuscrito e as hipóteses levantadas pelos historiadores Felix Garzón Maceda (1916) e Guillermo Furlong (1947) sobre sua procedência e autoria, nos detemos, também, nas evidências de intertextualidade que o texto nos oferece e compartilhamos algumas breves análises dos conteúdos dos capítulos que compõem o Libro.

Palavras-chave: Libro de cirugía. Manuscrito de medicina e farmácia. Reduções jesuíticas. América platina. Século XVIII.

\section{ABSTRACT}

\footnotetext{
${ }^{1}$ Doutora em História, Programa de Pós-Graduação em História da Universidade do Vale do Rio dos Sinos(UNISINOS) e-mail:ecdfleck@terra.com.br

${ }^{2}$ Doutor em Letras, Bibliotecário daBiblioteca Central da Universidade de Kiel(Alemanha).

e-mail: obermeier@ub.uni-kiel.de
} 
In this article, we present a preliminar analysis of the Libro de cirugía, dated 1725, an anonymous medicine and pharmacy manuscript, which is extant in the convent of the Franciscan Order of Catamarca, Argentina, and is still unpublished. Its transcription and analysis will contribute significantly to reconstruct the scientific culture achieved in La Plata-region) in the 18th century concerning the medicinal knowledge and practices in the region especially in the Jesuitic reductions. Besides discussing the title given to the manuscript and the hypotheses raised by historians Felix Garzón Maceda (1916) and Guillermo Furlong (1947) about its provenance and authorship, we dedicate ourselves to the issue of intertextuality in the manuscript and will impart a brief content analysis of selected chapters in it.

Keyword: Libro de Cirugía. Manuscript of medicine and pharmacy. Jesuitic reductions. Platin America. 18th century.

\section{Considerações Iniciais}

Apesar da significativa produção dos jesuítas sobre a natureza e os costumes das gentes do Novo Mundo, poucos foram os historiadores que se dedicaram a analisá-los levando em conta o papel que desempenharam na história intelectual do Renascimento e dos inícios do período moderno. Historiadores como Di Liscia (2002), Millones Figueroa; Ledezma (2005), Del Valle (2009) e Asúa (2014; 2010) se inscrevem em uma vertente historiográfica recente de reavaliação da atuação dos jesuítas na construção da chamada ciência moderna, destacando o papel que desempenharam na criação de redes de conhecimento e na formação de uma epistemologia particular no século XVIII. ${ }^{3}$ Em seus trabalhos enfatizam, sobretudo, a importância dos colégios da Companhia de Jesus instalados nas várias regiões em que seus membros atuaram, para a circulação de saberes e a prática de experimentalismos, dos quais resultou tanto a validação, quanto a contestação de práticas e saberes consagrados na Europa. $^{4}$

Alguns membros da Companhia, a despeito de uma assimilação seletiva de ideias caras à Ilustração, produziram notável conhecimento científico baseado na observação e na experiência e fundamentado no produtivo diálogo que mantiveram com a ciência e a

\footnotetext{
${ }^{3}$ É importante ressaltar a posição privilegiada ocupada pela Companhia de Jesus na produção e divulgação do conhecimento científico e etnográfico americano, pois, como bem observado por alguns estudiosos, seus membros conviveram "con los indígenas y en un medio ambiente lleno de objetos naturales 'novedosos' y por lo tanto esperando su catalogación", cumprindo "una importante función en la búsqueda de información", sendo também responsáveis por uma "escritura liminal", que ocupou "un lugar intermedio entre el orden letrado y las fronteras" (DEL VALLE, 2009, p. 52). ${ }^{4}$ Para Miguel de Asúa, "hay suficientes elementos para concluir que [...] ya desde la época de los jesuitas (antes de su expulsión en 1767) hubo en el Río de la Plata episodios y personajes 'modernizadores' [...] en las misiones se desplegaba una interesante actividad científica como lo demuestran los casos del astrónomo Buenaventura Suárez [...] y los autores de las 'historias naturales jesuitas del Nuevo Mundo' o los manuscritos de materia médica. Hace bastante que vengo argumentando que a mediados del siglo XVIII el frente más avanzado de la ciencia en el Río de la Plata se ubicó en las misiones del Paraguay histórico" (ASÚA, 2010, p. 192-193).
} 
filosofia modernas. ${ }^{5}$ Esta singular posição se traduziu no expressivo número de obras escritas por integrantes da ordem, tais como as Histórias Naturais e as Matérias Médicas, cuja análise permite a reconstituição do conhecimento científico por ela apropriado, difundido e produzido ao longo do século XVII e na primeira metade do século XVIII. ${ }^{6}$ Para além desta peculiar condição da Companhia de Jesus, e dadas as condições em que se deu o avanço colonial sobre as terras americanas, somadas à personalidade e aos talentos de cada missionário e ao isolamento a que muitos deles estiveram sujeitos, é preciso, também, considerar que muitos destes registros sofreram inegáveis influências das experiências vividas e das trocas interculturais que estes padres e irmãos vivenciaram. ${ }^{7}$

Esta dupla constatação parece justificar a proposição de estudos sobre o destino dado aos manuscritos de medicina, botânica e cirurgia - sobretudo daqueles que ainda se mantém inéditos - redigidos por padres e irmãos da ordem, nos séculos XVII e XVIII, e aos acervos das bibliotecas jesuíticas logo após a expulsão da Companhia de Jesus da América hispânica, em 1767. Uma análise dos inventários dos bens da ordem, por exemplo, nos revela a presença de livros, medicamentos, utensílios e instrumentos nos colégios e reduções da Companhia de Jesus na América platina, demonstrando que eles foram, por excelência, espaços de circulação de ideias - mediante a formação de redes de conhecimento - e de experimentalismos, que promoveram tanto a criação, quanto a validação de práticas e saberes (AMANTINO; FLECK; ENGEMANN, 2015). Estes dados evidenciam que em muitos desses colégios e reduções da ordem, encontraremos pensadores - como proposto pelo historiador equatoriano Cañizares Esguerra (2007) - que, apesar de habitarem regiões marginais no cenário intelectual do período - áreas consideradas apenas e tradicionalmente como receptoras de conhecimentos produzidos em outras partes do mundo -, foram decisivos na construção de determinados conhecimentos.

Neste artigo, apresentamos uma análise preliminar do Libro de cirugía, de 1725, um manuscrito anônimo de medicina e farmácia, ${ }^{8}$ que se mantém inédito até hoje. ${ }^{9} \mathrm{O}$ primeiro

\footnotetext{
${ }^{5}$ A ciência "recentemente designada de 'ciência jesuíta' ou 'filosofia natural jesuíta”" pode ser caracterizada, segundo o historiador português Luís Miguel Carolino, "como uma corrente multifacetada", que, apesar de "marcadamente heterogênea [e] com fortes tensões internas" manteve "diálogo constante com o debate filosófico e científico seu contemporâneo" (CAROLINO, 2009, p. 258-259).

${ }^{6}$ Para Millones Figueroa e Ledezma, os jesuítas incorporaram e assimilaram paulatinamente as ideias e os métodos de estudo da Ilustração, mas isto não significou "un rechazo absoluto del estudio de la naturaleza inspirado por la maravilla y el asombro que infundían las complejidades y misterios del mundo natural americano" Assim, a produção de um conhecimento baseado na observação e na experiência - tão caro aos jesuítas - "no ensombreció la fascinación por los mistérios de la naturaleza" (MILLONES FIGUEROA; LEDEZMA, 2005, p. 22).

${ }^{7} \mathrm{Se}$, por um lado, a incorporação de "aspectos de los lenguajes y las cosmovisiones aborígenes" pelos jesuítas conferiu, segundo Asúa, uma das "características distintivas de la ciencia en las misiones del Paraguay" (ASÚA, 2010, p. 193), por outro, nem sempre "hubo interés en reconocer de donde emanaban tales saberes", o que, no entanto, não impediu que padres e irmãos da Companhia iniciassem "un proceso apropiativo del manejo de la flora y la fauna con fines medicinales", com o propósito de "acceder al conocimiento exacto de sus propiedades y aprender a reconocer las especies en el campo, en medio de otras miles, recogerlas y cultivarlas, separando hojas, semillas, frutos o raíces, estudiando los jugos y las cocciones, los ungüentos y las pomadas. Un proceso complejo, que requiere del ensayo y error, de un saber basado en la experiencia y en la razón, en la práctica y en la teoría" (DI LISCIA, 2002, p. 296-299).

${ }^{8}$ O Libro de Cirugía possui nove capítulos: "1 Capítulo: Dispensário Médico, conteniendo diferentes fórmulas magistrales de medicamentos, para ser administrados por via oral o em aplicaciones externas; 2 Capítulo: Anatomía del cuerpo
} 
historiador a mencioná-lo e a descrevê-lo foi Félix Garzón Maceda, ${ }^{10}$ que, em sua obra $L a$ Medicina en Córdoba. Apuntes para su Historia, de 1916, traz extratos facsímiles de algumas poucas páginas do manuscrito original, que se encontra na Biblioteca do convento franciscano de Catamarca, na Argentina. ${ }^{11}$ Já a descrição detalhada realizada por Guillermo Furlong, que parece não ter tido contato com o manuscrito original, é inteiramente tributária daquela feita por Garzón Maceda. Foi, contudo, o historiador jesuíta quem, pela primeira vez, atribuiu ao irmão jesuíta Pedro de Montenegro a autoria do manuscrito, ${ }^{12}$ questão que será discutida ao longo do artigo.

A transcrição e análise deste manuscrito ${ }^{13}$ contribuem significativamente para a reconstituição da cultura científica vigente na América platina do Setecentos, principalmente, no que concerne aos saberes e às práticas medicinais empregadas nas reduções jesuíticas (ASÚA, 2010). Além de nos debruçarmos sobre o título dado ao manuscrito, discutiremos as hipóteses levantadas por Garzón Maceda e por Guillermo Furlong quanto à procedência e à autoria do manuscrito, ${ }^{14}$ bem como as evidências de intertextualidade ${ }^{15}$ que o texto nos oferece, compartilhando, ainda, algumas breves análises dos conteúdos dos capítulos que compõem o Libro.

humano; 3 Capítulo: El tratado de sangrar; 4 Capítulo: enfermedades de la cabeza; 5 Capítulo: Enfermedades del pecho; 6 Capítulo: Enfermedades de la cavidad abdominal; 7 Capítulo: Enfermedades de las Mujeres; 8 Capítulo: Tratado de las Fiebres; 9 Capítulo: Tratado sobre el pulso: orina y crisis. Algunos tratamientos quirúrgicos; Medidas para curar el 'morbo gálico' y el Escorbuto (ACERBI CREMADES, 1999, p. 19).

${ }^{9}$ Mesmo que se considere que o manuscrito não tenha tido um jesuíta como autor, é plausível supor que tenha integrado o acervo de alguma biblioteca jesuítica, pelo menos durante certo tempo. Se admitimos que o texto que analisamos, seja, efetivamente, uma cópia feita entre os anos 1730 a 1740, pode-se aventar que esta versão tenha integrado o acervo de uma das bibliotecas da ordem até 1767 , inclusive, como legado daquele que o possuía após sua morte.

${ }^{10} \mathrm{O}$ manuscrito constitui-se "de un volumen con más de 600 páginas, escrito con letra pequeña y apretada, intercalando muchos dibujos del instrumental quirúrgico usado para diversas intervenciones. Incluye un apéndice, escrito con letra diferente y quizá por eso de otro autor o colaborador de la obra figurando en ella el año de edición, 1725" (GARZÓN MACEDA apud ACERBI CREMADES, 1999, p. 19).

${ }^{11}$ Sobre a localização do manuscrito original, cabe ressaltar que, assim como Garzón Maceda, em 1916, e Guillermo Furlong, em 1947, também Charles E. O'Neill e Joaquin Maria Dominguez, no verbete Pedro Montenegro, inserido no Diccionário Histórico de La Companía de Jesús (2001), informaram que o irmão jesuíta "Escribió libros de medicina en español y guaraní. Sus principales obras fueron Matéria Médica Misionera (1710), con 148 ilustraciones hechas por él mismo, y 'Libro de Cirugía' (1725), aún inédito, que se conserva en la biblioteca del convento franciscano de Catamarca (Argentina)"(O'NEILL; DOMINGUEZ, 2001, p. 13-15, grifo nosso)

${ }_{12}$ Posicionando-se em relação à polêmica quanto à possibilidade de o Libro de Cirugía ter sido escrito por um frei franciscano - de nome Pacheco -, o historiador jesuíta Guillermo Furlong (1947, p. 74) afirmou que "Montenegro es el indiscutido autor de la tan zarandeada Matéria Médica Misionera pero, a nuestro parecer, es el igualmente el autor del Libro de Cirugía que, en 1916, dio a conocer el doctor Félix Garzón Maceda en magna y eruditísima historia de la 'Medicina de Córdoba"".

${ }^{13}$ Agradecemos a inestimável colaboração dos graduandos em História Letícia Mallmann de Souza, Bernardo Ternus de Abreu e Leonardo Cirra, que atuaram como bolsistas de Iniciação Científica junto ao projeto de pesquisa "As artes de curar em dois manucristos jesuíticos inéditos do Setecentos", desenvolvido, sob minha coodenação, junto ao Programa de PósGraduação em História da UNISINOS.

${ }^{14}$ A transcrição e análise que realizamos até o momento nos leva a formular a hipótese de que as partes intituladas Tratados sejam transcrições na íntegra de obras de referência já publicadas, e que as partes intituladas Enfermidades sejam autorais, conciliando passagens extraídas de outros autores com experiências realizadas pelo autor-compilador. No entanto, somente a conclusão da transcrição e da análise da versão do manuscrito em questão poderá trazer informações mais conclusivas sobre a provável autoria.

${ }^{15} \mathrm{O}$ conceito de intertextualidade que orienta as reflexões expostas no presente artigo está em concordância com o desenvolvido por Julia Kristeva $(1974$; 1981) - que nomeia e determina o conceito com base em Mikhail Bakhtin nas obras Semiótica I e II e Introdução a Semanálise. De acordo com ela "[...] todo texto se construye como mosaico de citas, todo texto 


\section{Sobre o título e a procedência do manuscrito}

O Libro de Cirugía, como denominamos - de forma abreviada - o manuscrito anônimo que analisamos, foi recentemente localizado na Biblioteca da ordem franciscana de Catamarca, na Argentina. ${ }^{16}$ Quanto à apresentação geral de seu exterior, observa-se que a encadernação é de couro marrom curtido, sem uso de cartaz para proteger as folhas, tendo sido feita, muito provavelmente, ainda à época jesuítica ou logo depois. ${ }^{17}$

A página original do título encontra-se muito deteriorada, como pode-se também observar na foto que se encontra na obra de Felix Garzón Maceda, de 1916, e, posteriormente, reproduzida por Guillermo Furlong, em livro de 1947. Assim como Furlong, outros autores também mantêm o título dado ao manuscrito por Garzón Maceda, dentre os quais destacamos José Penna, ${ }^{18}$ Ramón Pardal e Juan Aníbal Domínguez. ${ }^{19}$ Abaixo, apresentamos uma tentativa de reconstituição da página na qual consta o título e que tem sua leitura prejudicada pela falta de pedaços de papel e pela corrosão provocada pela tinta empregada.

\section{LIBRO DE [na página $545,{ }^{20}$ encontra-se menção a um texto de "Medicina, Cirugía y farmasia", por isso propomos que a continuação seja: MEDI-] \\ C[INA] \\ CIRUGIA, [BOTI-]}

es absorción y transformación de otro texto" (KRISTEVA, 1981, p. 190), o que seria o princípio da intertextualidade. Levamos em consideração, ainda, o afirmado por Gerard Genette (2006), em sua obra Palimpsestos: a literatura de segunda mão. Este autor entende intertextualidade como uma "[...] relação de co-presença entre dois ou vários textos, isto é, essencialmente, e o mais freqüentemente, como presença efetiva de um texto em um outro", sendo assim um dos cinco tipos de "transtextualidade" (GENETTE, 2006, p. 8). A aplicação do conceito de intertextualidade na análise do manuscrito considerará, portanto, o proposto por estes dois autores e a classificação de tipos de intertextualidade que podem ser encontrados na obra.

${ }^{16}$ Deve-se a Franz Obermeier a retomada de interesse neste manuscrito tido como extraviado e as gestões junto à Província Franciscana de la Asunción (Buenos Aires), para que o mesmo fosse disponibilizado aos pesquisadores nele interessados. Agradecemos ao Frei Jorge David Catalán, da Província Franciscana de la Asunción (Buenos Aires), pois por seu intermédio tivemos acesso a uma cópia digitalizada do manuscrito, que se encontra na Biblioteca da ordem em Catamarca, na Argentina.

${ }^{17}$ A encadernação não parece ser de época posterior ou ter sido feita por um encadernador profissional, o qual, seguramente, teria feito uma capa estável usando cartaz.

${ }^{18} \mathrm{O}$ prefácio foi publicado em Penna (1917). Neste trabalho, José Penna refere as fotografias de algumas páginas do manuscrito em uma passagem sobre o tema da peste mencionado no Libro.

${ }^{19}$ Pardal (1998, p. 110) faz referência ao farmacólogo Juan Aníbal Domínguez, que, em sua obra Contribuciones a la materia médica argentina, de 1928, menciona um manuscrito anônimo de Catamarca, escrito entre 1722 e 25, "y que lleva por título Libro de Medicina-Cirurgia y Botanica", que, certamente, é o manuscrito que estamos analisando. Dominguez tampouco parece ter tido contato com o manuscrito original, porque quando se refere ao uso do paico macho (Chenopodioum ambrosioides L.), apresentado no manuscrito como antihelmíntico e emenagogo, também recorre a Garzón Maceda.

${ }^{20}$ Esclarecemos que as páginas informadas no artigo correspondem à paginação da versão digitalizada do manuscrito que estamos analisando, uma vez que a paginação do texto original não é contínua. Na sequência da primeira parte do manuscrito (das páginas 1-513 da versão digitalizada), há um Apêndice, que também não tem paginação contínua. A segunda parte, por sua vez, tem outra paginação, sendo que o Apêndice desta parte apresenta paginação distinta da parte que $o$ antecede. 


\section{CA}

[Trecho em letra cursiva/acrescentado posteriormente] Aplicado a la libreria del convento de Catamarca, [marca que indica que o manuscrito integrava a biblioteca franciscana]

\section{Trasladado de au[tores]}

Graves y [doctos]

Para alivio de los Enfermos

Escrito en estas Doctrinas ${ }^{21}$

De la Compañia de Jesus

Año de 1725

Aplicado [muito provavelmente uma repetição da nota anterior com menção ao Convento de Catamarca] [ilegível]

A letra "c" da segunda linha ainda se encontra legível, o que nos leva a propor que a palavra completa seja "Medicina". Concordando com o proposto por Garzón Maceda, defendemos que "Botica" seja a palavra que consta na terceira linha. É possível, contudo, que o termo também fosse "Botanica", mas acreditamos que ele não exprima as propriedades medicinais atribuídas às plantas descritas no texto.

Outra controvertida questão é a datação do manuscrito. Para Garzón Maceda, há uma "segunda parte" do texto com datações internas que não permitem dizer que a data do frontispício se refira ao texto inteiro. ${ }^{22}$ Pode-se supor que esta parte tenha sido inserida, posteriormente, como anexos atualizados e encadernados junto com a primeira ou, então, que se constitua em um segundo texto, talvez de outro autor, como parece sugerir a menção feita à data de 1736, na p. 55 da segunda parte do manuscrito, em uma grafia que parece ser um pouco mais livre do que a empregada na primeira parte do manuscrito.

Como observado em muitos manuscritos jesuíticos rioplatenses do período colonial, também este não tem registrado o nome de seu autor ou do compilador. O Prólogo, que conta com apenas três páginas, também não foi assinado. Assim, não sabemos ao certo quem o escreveu e tampouco se seu autor é também o autor do texto inteiro ou apenas da primeira parte. ${ }^{23} \mathrm{O}$ texto encontra-se bastante danificado, razão pela qual conseguimos reconstituir apenas uma parte dele, na qual encontramos explicitada a razão para a escrita deste manuscrito: "Moviome a escrivir [...] do hallar en Libro a [...] preciso ... nan continuamente

\footnotetext{
${ }^{21} \mathrm{O}$ texto, como informado em sua capa, teria sido escrito nas Doctrinas, isto é, nas reduções. Não há, no entanto, menção explícita à autoria ser de um padre ou de um irmão jesuíta. É plausível supor que seu autor tenha sido efetivamente um padre ou irmão jesuíta, religiosos que, muitas vezes, por modéstia, não informavam seus nomes nas obras que escreviam. Por outro lado, as informações extraídas de obras que não se encontravam disponíveis nas bibliotecas dos colégios ou das reduções jesuíticas nos leva a pensar na possibilidade de que o autor-compilador do manuscrito não seja um religioso.

${ }^{22}$ Para apurar esta possibilidade, será necessário considerar as menções feitas ao longo do manuscrito a obras posteriores a 1725, bem como as diferenças de letra e, especialmente, de estilo de escrita, no caso de haver mais de um autor.

${ }^{23}$ A semelhança entre a letra do autor do prefácio e a do autor/compliador da primeira parte do texto parece ser um indicativo que estes dois textos, que compõem a primeira parte do manuscrito, foram escritos pela mesma pessoa. Podese, ainda, supor que ele tenha sido o responsável por reunir as duas partes, que apresentam letras diferentes. Observa-se que a segunda parte não conta com frontispício e apresenta letras distintas da primeira parte ao longo dos textos que a compõem.
} 
po...antes no po.... do llevar muchos Libros,... allaba falto ... otras veces de aquellos que tr[ataban] la mane[ra...] del caso particular que se ofrecia" (LIBRO DE CIRUGÍA, 1725, p. 9).

O que se pode deduzir dessa passagem fragmentada é que o autor-compilador do manuscrito pretendeu reunir textos de referência de Medicina e de Cirurgia para consulta imediata durante as viagens que realizava para o atendimento de doentes. $O$ trecho deixa claro também a finalidade prática que o texto teria: "para mejor intelligencia y asiento en la administracion de los remedios, que se deben aplicar" (LIBRO DE CIRUGÍA, 1725, p. 13).

A ausência de menções a outros jesuítas no prefácio, bem como de uma simbologia jesuítica no frontispício do manuscrito causou grande estranheza em Garzón Maceda, mas a análise de outros textos rioplatenses da época tem mostrado que poucos têm capas ou frontispícios com símbolos jesuíticos, o que se observa até mesmo em manuscritos de sermões que seguramente tiveram autores jesuítas. Pode-se, no entanto, aventar, acompanhando Garzón Maceda, que o texto tenha sido uma cópia para uso pessoal de um original jesuítico. Segundo este autor (GARZÓN MACEDA, 1916, p. 475-496), o manuscrito teria sido usado pelo "celebre Padre Pacheco, Franciscano". Para discutir esta possibilidade por ele aventada, apresentamos algumas informações sobre o frei Pedro Luis Pacheco.

Este frei franciscano, que nasceu em Buenos Aires, em 1762, e morreu em 1823, é conhecido pela viagem que fez a Roma, em 1810, com o propósito de denunciar o estado de deseleixo em que se encontrava o clero rioplatense. Em sua obra, Garzón Maceda (1916, p. 118-161) informa que o frei foi professor de Cânones na Universidad de Córdoba, e que praticou medicina sem ser médico, tanto em Córdoba, quanto em La Rioja e Catamarca, o que poderia tê-lo levado a ter consigo uma cópia do manuscrito que analisamos. Não sabemos se frei Pedro Luis Pacheco teve atuação destacada no convento de Catamarca durante o período em que atuou na cidade e a documentação encontrada no Arquivo da ordem não parece justificar a hipótese levantada por Garzón Maceda.

Pode-se, em razão disso, aventar a possibilidade de tratar-se de outro "celebre Padre Pacheco", que não o frei franciscano. Este padre seria o dominicano José Joaquín Pacheco, personagem importante na história eclesiástica de Tucumán, que atuou como provincial e fundou o convento dominicano de Tucumán, em $1785 .{ }^{24}$ Esta possibilidade merece ser considerada, uma vez que após a expulsão dos jesuítas, os dominicanos ficaram encarregados da administração de Yapeyú, San Borja, San Miguel, San Nicolás, Mártires, San Carlos, San Ignacio Miní, Trinidad, San Cosme e Nuestra Señora de la Fe, sendo que outras missões foram entregues aos franciscanos e aos mercedários. (AMENTA, 2003).

Os dominicanos foram encarregados do cuidado espiritual das atuais províncias de Tucumán e Catamarca. Mas se instalaram na região somente em 1781, muito tempo depois

${ }^{24}$ Para a história desta ordem, ver: http://www.op.org.ar/?page_id=168. E, ainda, Esponera Cerdán (1992). 
de outras ordens. Em 1784, uma Real Cédula cedeu aos dominicanos a igreja e o colégio jesuíta de San Miguel de Tucuman, hoje San Francisco, que seriam dados um ano depois, em 1785, aos franciscanos. Por Real Cédula de Carlos III, de 1786, foi concedido aos padres dominicanos o convento que ainda hoje possuem em San Miguel. Frei Pacheco foi também o fundador do colégio de San José de Lules, em 1781 (hoje San Isidoro de Lules), no lugar em que anteriormente havia funcionado uma redução jesuítica.

Desde 1787, os capítulos provinciais dominicanos nomearam missionários para as regiões da sua jurisdição, sendo que alguns foram também párocos ou administradores de paróquias em zonas rurais. Sabemos que frei José Joaquín Pacheco, por razões de saúde, passou os seus últimos anos no convento de Buenos Aires. Teria ele entregue seus manuscritos à biblioteca de outra ordem antes de retornar a Tucumán? E, caso o tenha feito, por que não os doou a uma biblioteca de sua própria ordem? Que outros manuscritos do convento dominicano podem ter sido destinados ao convento franciscano de Catamarca?

Para responder a estes questionamentos, partimos da suposição de que frei José Joaquín Pacheco, ao fundar o convento dominicano de Tucumán, tenha, certamente, pensado em nele instalar uma biblioteca. É correto também aventar que o frei soubesse que alguns livros provenientes de bibliotecas jesuíticas, em especial, da de Córdoba, que haviam sido confiscados após o decreto de expulsão da ordem, eram vendidos por arrematadores particulares. Sobre a biblioteca de Córdoba, existe um catálogo (1757), organizado por Alfredo E. Fraschini (2003), e muitos estudos (FERREIRA; PAGE, 2000), sendo que tanto Luis Martínez Villada (1919), quanto Silvano Benito Moya (2012) confirmam que frei Pacheco comprou livros da biblioteca jesuítica de Córdoba.

La entrega de la biblioteca a la Universidad no encerraba para las temporalidades un deseo de "piedad regia", como se gustaba invocar frecuentemente, sino que los libros se habían puesto a la venta [...]. Desde Buenos Aires se autorizó, por ejemplo, en 1805, que se le vendiera al franciscano Fr. José Joaquín Pacheco los libros que quisiera al precio de tasación para el convento de Tucumán (VILLADA, 1919, p. 185).

Em relação à passagem acima, cabe destacar que o autor refere que frei José Joaquim Pacheco era franciscano, o que é incorreto, pois era dominicano. Pode-se, no entanto, supor que Martínez Villada tenha se confundido em relação ao verdadeiro nome do frei franciscano, sobre quem já discorremos, o que poderia reforçar a hipótese de que o manuscrito tenha sido comprado, de fato, por franciscanos que o agregaram ao acervo do convento de Catamarca. Isto, no entanto, não elimina a possibilidade de o manuscrito que 
analisamos - o Libro de Cirugía - tenha sido encontrado diretamente em uma redução jesuítica assumida pelos franciscanos após a expulsão da ordem.

Pode-se, ainda, cogitar a possibilidade de que um clérigo secular tenha legado sua cópia do manuscrito original à uma biblioteca da ordem franciscana ou dominicana, durante o período de sua atuação junto às doutrinas da região de Tucumán e Catamarca. No momento, no entanto, não temos como apresentar, em caráter definitivo, uma conclusão quanto à procedência e, em especial, em relação à autoria do manuscrito, aspecto que abordaremos na continuidade. ${ }^{25}$

\section{Sobre a autoria do manuscrito e as evidências da apropriação e circulação de saberes}

O historiador argentino Guillermo Furlong (1947, p. 62-81) atribuiu a autoria do manuscrito ao irmão jesuíta e "exímio médico" Pedro de Montenegro, ${ }^{26}$ autor da Matéria Médica Misionera, ${ }^{27}$ negando enfaticamente que o texto possa ter sido escrito por outro irmão jesuíta, Marcos Villodas, o suposto autor de Pojhã Ñana, manuscrito que versa sobre o uso medicinal de plantas e que está integralmente escrito em guarani. ${ }^{28}$ Infelizmente, Furlong não se deteve na descrição ou análise dos elementos que comprovem a autoria do Libro.

A circulação de manuscritos de ciência nas reduções era usual na época, conciliando o saber acadêmico de médicos e boticários e as experiências realizadas por religiosos como o irmão jesuíta Montenegro. ${ }^{29}$ Estes manuscritos eram copiados e compilados, obedecendo a

\footnotetext{
${ }^{25}$ A reflexões sobre a função autor e as práticas de escrita do século XVIII foi realizada com base em Roger Chartier, Faulhaber e Lopes (2012), enquanto que a questão da "escrita erudita" e das "autoridades" do mundo científico foi examinada a partir da perspectiva de Michel de Certeau $(1982,1994)$.

${ }^{26}$ Sobre Pedro Montenegro, ver mais em: Furlong (1947), Martin; Valverde (1995), Anagnostou (2011), Fleck (2015) e Fleck, Rodrigues e Martins (2014).

${ }^{27}$ Escrita em 1710, Matéria Médica Misionera tem 458 páginas, além de 148 desenhos de plantas feitos à mão. Existem várias versões impressas da obra: a primeira foi publicada em 1888, por Ricardo Trelles, na Revista Patriótica Del Pasado Argentino; a segunda, data de 1945, e foi editada pela Biblioteca Nacional de Buenos Aires, se encontrando disponível em formato digital na Biblioteca Virtual del Paraguai, e há, ainda, outra versão completa foi publicada por Carmen Martín Martín, em 1995.

${ }^{28}$ Uma das versões do manuscrito atribuído a Villodas se encontra na Wellcome Library, de Londres, que o adquiriu em 1962, junto com outras peças da coleção do Dr. Francisco Guerra (1974), bibliófilo e historiador da medicina. Por esta razão, o Manuscrito Villodas é também conhecido como MS Londres. Sabe-se que uma versão, em guarani, foi encadernada junto com uma obra de Gregório Lopez e se encontra na Biblioteca Nacional de Madrid, com notáveis variantes. Outra versão manuscrita, abreviada e combinada com uma versão espanhola da Matéria Médica de Pedro Montenegro, foi localizada na Biblioteca do Iberoamerikanisches Institut de Berlim e, recentemente, apresentada por Franz Obermeier (2017).

${ }^{29}$ A história natural e a farmácia missioneira podem ser consideradas como "as duas facetas principais do naturalismo jesuítico na América do Sul", por outro, não devem ser percebidas como "precursoras deficientes das ciências atuais ou como cópias insuficientes dos modelos europeus, mas como formas independentes e singulares da história da ciência"
} 
interesses práticos daqueles que os possuíam, e muitos deles provêm, seguramente, da Matéria Médica de Montenegro, como já apontado por Miguel de Asúa (2014, p. 119-123). A importância deste irmão jesuíta para a farmácia e a medicina rioplatense não deve ser, no entanto, tomada como razão inquestionável para atribuir a ele a autoria do Libro de Cirugía. No manuscrito que estamos analisando não encontramos, até o presente momento, qualquer referência explícita à pessoa dele ou mesmo à Matéria Médica.

No caso do Pojhã Ñana, a referência feita ao irmão Marcos Villodas na segunda parte do manuscrito também não confirma que ele seja o autor, uma vez que são feitas apenas menções a receitas que compõem o manuscrito a ele atribuído (OTAZÚ MELGAREJO, 2014). No manuscrito em análise, encontramos referências a certas plantas medicinais cujas virtudes também se encontram descritas na Matéria Médica, mas isto, evidentemente, pode decorrer do fato de que estas plantas eram bastante conhecidas e tinham uso geralizado em algumas receitas empregadas na região platina. Dentre as referidas, destacamos o célebre bálsamo de "Aguaribay", mencionado nas páginas 145, 243, 259 e 261 e 290 do manuscrito digitalizado, com destaque para as suas diferentes aplicações, sendo que em uma das passagens, à p. 125, o autor-compilador refere, explicitamente, sua experiência com a utilização desse bálsamo. Já na p. 260, encontramos a menção ao "Caayci", um remédio tradicional das reduções, também referido como "Calsi" na p. 332 do manuscrito. Sobre sua utilização, nos informa o padre Guevara: "El Caayci lo vsan en lugar de incienso y hacen de el balsamo contra heridas y llagas" (GUEVARA, 1908, p. 93). Essas passagens parecem comprovar que os saberes e práticas de cura rioplatenses, e que, efetivamente, circulavam na região, estão presentes no manuscrito, mas isto não significa, necessariamente, que tenham sido transmitidos pelo irmão jesuíta Montenegro ou por intermédio da obra que escreveu.

A importância do Libro de Cirugía não se reduz às virtudes e às receitas de plantas medicinais nativas da América platina, podendo ser também observada nos autores referidos pelo autor-compilador ao longo dos capítulos do manuscrito. Garzón Maceda também chegou a indagar-se sobre a influência que os autores citados teriam exercido sobre o autor-compilador do manuscrito, sem, no entanto, realizar uma análise mais aprofundada em torno da apropriação e circulação de saberes na América platina na primeira metade do século XVIII. Em um exame preliminar, localizamos mais de cinquenta autores médicos citados ao longo dos capítulos do Libro.

As primeiras evidências de intertextualidade se encontram no Prólogo, no qual o autorcompilador do manuscrito faz referência às obras que consultou: ${ }^{30}$

(ANAGNOSTOU; FECHNER, 2011, p. 175). Esta singularidade, segundo ela, fica evidenciada na "experimentação e na incorporação do saber etnofarmacêutico indígena", que decorreu da "posição relativamente imparcial e aberta dos jesuítas frente aos indígenas, baseada na espiritualidade inaciana", que possibilitou "um intercâmbio intenso e persistente no campo da medicina" (ANAGNOSTOU; FECHNER, 2011, p. 190).

${ }^{30}$ Ver mais em: Garzón Maceda (1916, p. 477) e, também, em Asúa (2014, p. 158). 
[...] todo lo contenido lo he sacado de autores clásicos y doctos que son para la medicina de las obras del doctor Gordino [sic], ${ }^{31}$ del Libro de la peste del doctor Luis Mercado, ${ }^{32}$ del Compendio de don Juan de la Torre, ${ }^{33}$ del médico caritativo, por el licenciado Félix Borbón, ${ }^{34}$ de "La llave de oro" del doctor Trapiella, ${ }^{35}$ del "Tesoro" de Juan Viguier, ${ }^{36}$ y del libro del doctor P. Fray Agustín Farfán, ${ }^{37}$ y de los experimentos del doctor Gerónimo Soriano. ${ }^{38}$ Para lo pertinente a cirurgia me he valido de la obra del licenciado Dionisio Daza ${ }^{39}$ y la del Doctor Juan Calvo, ${ }^{40}$ de la cirurgia de Antonio de la Cruz, ${ }^{41}$ de la del doctor Antonio de Robledo, ${ }^{42}$ de la del licenciado Porres ${ }^{43}$ y del Cirurgiano Caritativo. La botica é sacada de [...] (LIBRO DE CIRUGÍA, 1725, p. 9).

\footnotetext{
${ }^{31}$ Trata-se de: Lilio de medicina o Lilium medicinae, escrito por Bernardus de Gordonio, em 1308, e editado em Toledo, na gráfica de Juan de Villaquiran impresor de libros [e] de Gonçalo de Auila mercader de libros, 1513. Provavelmente, o autorcompilador recorreu a uma edição posterior, Medicinae Inscriptum. De morborum propè omnium curatione, septem particulis distributum ...Lugduni: Rovillius, de 1574.

${ }^{32}$ Trata-se de: Libro, en que se trata con claridad la naturaleza, causas, providencia, y verdadera orden y modo de curar la enfermedad vulgar, y peste que en estos años se ha divulgado por toda España. Madrid: Impr. del licenciado Castro, 1599.

${ }_{33}$ A obra de Juan de la Torre y Balcárcel intitula-se Espejo de la philosophia y compendio de toda la medicina theorica y practica por... Juan de la Torre y Balcarçel...Añadido y enmendado en esta impression el Tratado de Morbo Galico, Madrid: Por Juan Garcia Infançon [...], 1705.

${ }^{34} \mathrm{O}$ título completo do livro de Felipe Borbón é Medicina y cirugia doméstica, necessaria á los pobres y familiar á los ricos, trascripta del Medico caritativo, Valencia por Jayme de Bordazar y Artazú, 1705. No manuscrito, a obra aparece, muitas vezes, abreviada como "M.C".

${ }^{35}$ A obra intitula-se LLave de oro medicinal de la salud humana formada con desvelo por el Doctor Don Domingo Trapiella, $y$ Monte-Mayo, tendo sido publicada por Francisco Antonio de Villa-Diego, em Madri, no ano de 1713.

${ }^{36}$ Provavelmente, o autor usou a edição portuguesa da obra de Jean Vigier: Thesouro apollineo, galenico, chimico, chirurgico, pharmaceutico ou Compendio de remedios para ricos \& pobres: dividese em duas partes ... por Joam Vigier ... Lisboa: na Officina Real Deslandesiana, 1714.

${ }^{37}$ Trata-se de: FARFÁN, Agustín (O.S.A.). Tractado brebe de medicina, y de todas las enfermedades hecho por el padre fray Augustin Farfan doctor en mediçina, y religioso indigno de la orden de sant Augustin, en la nueua España, Mexico: en casa de Pedro Ocharte, 1592.

${ }^{38}$ Esta obra foi publicada sob o título de Libro de experimentos, em Saragoça, em 1598. Ressaltamos que as citações extraídas desta obra que constam no manuscrito correspondem, no entanto, a uma edição posterior, à "edición muy emendada: Valencia: Bordazar 1700".

${ }^{39}$ Trata-se de DAZA CHACÓN, Dionisio. Pratica y theorica de cirugia en romance y latin. Valladolid por Bernardino de S. Domingo 1584. Pode ser, também, DACA, Alfonsi. Artium et medicinae doctoris libri tres de ratione cognoscendi caussas $\mathcal{E}$ signa tam in prospera quàm aduersa valetudine vrinarum [...] Hispali [Sevilla] apud Alfonsum de la Barrera typographum, 1577, obra que se encontrava na Biblioteca jesuítica de Córdoba e na de Assunção.

${ }^{40}$ Trata-se de: CALVO, Juan. Libro de medicina y cirurgia que trata de las llagas en general y en particular y assi mesmo del morbo gallico, de la curacion de el. Barcelona: Jaime Cendrat, 1592, archive.org. Segunda parte de la medicina y cirurgia, que trata de las vlceras en general y particular, y del Antidotario, en el qual se trata de la facultad de todos los medicame[n]tos assi simples como compuestos segun Gal[eno]. en el libro quarto y quinto de la facultad de los simples, con otros tratados. Valencia: en casa de Iuan Chrysostomo Garriz, 1599.

${ }^{41}$ Trata-se de: CRUZ, Antonio de la. Tratado de Cirurgia para enseñanza de los practicantes, Lisboa, 1618. Até o presente momento, não localizamos qualquer exemplar desta obra em catálogos online de bibliotecas internacionais. Acreditamos que possa se tratar de outro livro do autor, como a Recopilaçam de Cirurgia composta pello Ldo. Antonio da Cruz; Acrecentada nesta sexta impressaõ pello D. Francisco Soares Feyo, E pello Licenciado Antonio Gonçalves. Lisboa: na officina de Henrique Valente de Oliveira, 1661 ( $1^{\text {a }}$ edição 1601$)$.

${ }^{42}$ Trata-se de: ROBLEDO, Diego Antonio. Compendio cirurgico util y provechoso a sus profesores. Madrid 1687. A paginação de mencões no texto se refere a quinta edição, Madrid: Joachin Sanchez, 1733.

${ }^{43}$ Trata-se de: PORRAS, Manuel de. Anatomía Galénico-Moderna, compuesta por el Dr. don..., cirujano de Su Magestad, de los Reales Hospitales de la Corte y Examinador del Real Protomedicato. Madrid: Susica, 1716.
} 
Dentre as obras com maior número de referências, estão Medico caritativo, de Felipe Borbón, ${ }^{44}$ que aparece, às vezes, na forma abreviada "M.C."; uma obra de Jean Vigier, que o autor-compliador cita como "Vig.", e a obra de Trapiella y Montemayor. Algumas das receitas referidas no manuscrito são extraídas diretamente das obras destes médicos ou de referências feitas a eles em outros textos. Temos, também, menções a observações e experiências realizadas por outros irmãos jesuítas, sendo que o autor-compilador deixa claro que estas lhe foram transmitidas oralmente ou através de cartas, sem que, contudo, especifique as reduções às quais os religosos se encontravam vinculados. Em uma tentativa de reconstituição da procedência das informações, constatamos que, em sua maioria, se referem à zona chiquitana de Mojos, o que parece apontar para possíveis contatos do nosso autor-compilador com religiosos da ordem que atuavam nesta região e, até mesmo, com aqueles que circulavam pelos caminhos que levavam à Santa Cruz de la Sierra.

Apesar das poucas menções feitas a médicos de outras regiões da América Latina, elas nos permitem demonstrar a amplitude de contatos que o autor tinha e quais os saberes e práticas de cura que, segundo ele, mereciam ser registrados. Infelizmente, não encontramos informações sobre frei Onofre Médico, associado a uma receita de Mechoacan, que consta na p. 85 da versão digitalizada do manuscrito; sobre Juliano Ortiz, de Lima, mencionado na p. 617, e sobre Dr. Domingo García, ${ }^{45}$ referido à p. 628, que, acreditamos, podem ter transmitido oralmente suas receitas e experiências com plantas medicinais nativas. ${ }^{46}$

Para além das reflexões suscitadas pelas recorrentes menções a certos autores, procuramos, também, verificar se as obras mencionadas no Prólogo se encontravam referidas no acervo da maior biblioteca jesuítica da época, a do Colégio de Córdoba. No já citado catálogo deste colégio (FRASCHINI, 2003), encontramos Espejo de la Philosophia, de Torre y Barcarzel; Cirugia, de Felipe de Borbón, sob o nome latinizado Philippus de Borbon; Chirurgia universalis, de Calvo, ou Ioannes Calvo, e Ratione cognoscendi infirmitates, de Alphonsus Daza. ${ }^{47}$ Os demais autores citados no Prólogo não se encontram relacionados no Catálogo do Colégio de Córdoba ou no Inventario do Colégio de Assunção, o que parece sugerir que o autor-compliador pode tê-los consultado em outros acervos que não os da Companhia de Jesus. Esta constatação nos permite indagar: teria o autor consultado alguma biblioteca privada e pacientemente se dedicado a copiar os trechos que lhe interessavam? Esta é uma especulação que, se confirmada, poderia nos levar a, mais uma vez, questionar o afirmado por Furlong, para quem o autor do manuscrito é o irmão jesuíta Montenegro.

\footnotetext{
${ }^{44} \mathrm{O}$ título completo da obra é Medicina y cirugia doméstica, necessaria á los pobres y familiar á los ricos, trascripta del Medico caritativo, Valencia por Jayme de Bordazar y Artazú, 1705.

${ }^{45}$ Garzón Maceda chegou, inclusive, a cogitar que Domingo García pudesse ter sido o autor do Libro, mas acabou concluindo que seria pouco provável.

${ }^{46}$ Não encontramos qualquer menção a Juliano Ortiz ou a Domingo García nas obras de José Toríbio Medina (1904-1907) e de Antonio Palau y Dulcet (1948), o que indica que ambos não publicaram obras de medicina.

${ }^{47}$ Cabe ressaltar que esse último livro consta no Inventário da Biblioteca jesuítica de Assunção, no qual se encontram também relacionados a obra de Gordonio e alguns outros livros de medicina. Ver mais em: Gorzalczany e Olmos Gaona (2006).
} 
O fato é que somente um maior investimento nas evidências de intertextualidade, nas caligrafias e nos estilos de escrita empregados nas duas partes do manuscrito, e, em especial, uma análise comparativa entre o Tratado de Cirurgia e a Matéria Médica, de Pedro de Montenegro, e o Pojhã Nana, atribuído a Marcos Villodas, poderá determinar tanto a autoria, quanto a data - ou período provável - em que o texto ou partes do manuscrito foram escritos.

\section{Compartilhando breves análises dos capítulos do manuscrito}

Neste tópico, compartilhamos os primeiros exercícios de análise dos sete capítulos já transcritos, a saber, Tratado Brebe del Modo de Sangrar ( $3^{\circ}$ capítulo), Enfermedades de la cabeza ( $4^{\circ}$ capítulo) Enfermedades del Pecho (5 $5^{\circ}$ capítulo); Enfermedades de la Cavidad Abdominal $\left(6^{\circ}\right.$ capítulo) Enfermedades de las mujeres ( $7^{\circ}$ capítulo), Tratado de las fiebres ( $8^{\circ}$ capítulo) e Capítulo del pulso, orina y crisis ( $9^{\circ}$ capítulo).

No terceiro capítulo da obra, Tratado brebe del modo de sangrar, encontramos uma descrição detalhada sobre como realizar uma sangria. Esse tratamento era empregado no tratamento de algumas doenças e consistia na retirada de sangue do enfermo, por meio de cortes feitos estrategicamente ou do uso de sanguessugas colocadas em locais definidos a partir dos sintomas da enfermidade. O procedimento muda para cada caso, assim como o membro do corpo a ser cortado, o instrumento a ser utilizado e as indicações que acompanham o processo. Há, segundo o autor-compilador, uma sangria específica para cada enfermidade.

\footnotetext{
Como sangra la vena cefalica, ò vena de la cabeza? Poniendo al enfemo sobre el lado contrario, recogiendole la camisa hasta el hombro, de manera que no se caiga sobre la ligadura, y le pondrè la cinta tres dedos más arriva de donde se hia de picar, con una cinta de media seda de un dedo de ancho, y romperè la vena longitudinamente (GRAVES y [doctos], 1725, p. 167).
}

Nele, encontramos, também, algumas ilustrações de veias e de instrumentos cirúrgicos, utilizados no procedimento, tais como o sajador, utilizado pelos sajadores, que faziam as 
sangrias, bem como dietas indicadas para antes ou depois da sangria, sendo que as mais frequentes prevêem a ingestão de vinho tinto diluído em água antes do procedimento. Alguns alimentos, no entanto, não deveriam ser ingeridos por certos enfermos, como no caso da sangria realizada em uma mulher grávida:

\begin{abstract}
Y si fuese muger, y estuviese preñada, podrase sangrar de la vena del arca? No la sangre sino de la vena comun de todo el cuerpo, y le pondré en el ombligo antes de hacerse la sangria un poco de carne a medio asar, õ una tortilla de huevos, õ una tostada de pan mojado en vino, y polvoroado en canela (GRAVES y [doctos], 1725, p. 173).
\end{abstract}

No capítulo De las enfermedades de la cabeza, encontramos receitas cujos ingredientes eram unhas de mamíferos, tais como veados, cães e antas, estas últimas referidas como "la gran bestia", que, segundo o autor-compilador, auxiliavam no tratamento de epilepsia. Outras delas previam a ingestão de partes de sapos e caranguejos, como evidenciado nesta passagem: "Dicen que el Brazo derecho del sapo, si lotra en los inos los libra delos accidentes epilépticos" (GRAVES y [doctos], 1725, p. 196). Constatou-se, ainda, que, neste capítulo, apesar de o autor recorrer com frequência à obra Médico Caritativo, de Felipe Borbón, e a outras autoridades científicas, ele o faz com menos frequência do que em outros, o que poderia apontar para uma narrativa mais autoral. No entanto, como nos demais capítulos, existem algumas diferenças na caligrafia, que nos levam a duvidar de que foi escrito ou copiado por apenas uma pessoa. Nas laterais das páginas deste capítulo encontramos anotações com letra diferente daquela empregada no texto, o que, no entanto, não exclui a possibilidade de que elas tenham sido posteriormente acrescentadas por um leitor ou revisor na versão do manuscrito que estamos analisando.

No $5^{\circ}$ capítulo, que trata das enfermidades do peito e da voz, o autor-compilador refere um caso de convulsão: "[...] Muchas veces, se experimenta alguna cosa de convulsion, en este caso no usaremos de medicamentos volatiles sin mescla de laudano, u opio; mejor es mitigar los accidentes con medicamentos templados, como el ambar de cuentas preparado, las mirra en polvo, y el Incienso macho [...] (GRAVES y [doctos], 1725, p. 249).

Os quadros convulsivos remetem à epilepsia, doença citada na Tabla de las cosas notables, na qual são listadas outras enfermidades. As crises epilépticas, vale ressaltar, foram compreendidas historicamente sob um viés sobrenatural, e, por provocarem movimentos desordenados do corpo humano, chegaram a ser descritas como um fenômeno ocasionado pela ação de forças demoníacas. No caso do Libro de Cirugía (1725), no entanto, o autorcompilador não faz menção a elementos mágico-religiosos para descrever suas causas ou 
para tratá-la, o que parece apontar para uma forma distinta, isto é, científica, de tratar convulsões e epilepsias, reforçando a possibilidade de que o autor-compilador não tenha sido um religioso.

O sexto capítulo do manuscrito se refere às enfermidades da cavidade abdominal e contempla terapêuticas indicadas para conter as dores de estômago, tratar a disenteria e a prisão-de-ventre, as diarreias, as verminoses - muito comuns entre os indígenas nas reduções jesuíticas -, as hemorroidas e, ainda, as enfermidades do baço e do fígado. No subcapítulo sobre vômitos, encontramos registrada a atuação do autor-compilador na cura de uma grave enfermidade que acometia um indígena da redução de São Miguel, a quem foram administrados os santos sacramentos e a "medicina siguiente":

[...] Estando yo en s.n mig. Me avisaran de la enfermedad de un Indio. q.e hera colica flatuosa, àla q.l llaman ellos Yabirù. Tenia el vientre inchado como un tambor, y ya conados los stos Sacramentos: dispuselè la medicina siguiente. De medula de Patas de Vaca liquida quatro onz, junto con quatro onz. de vino, y una cucharada de sal, de hise levantar un heruor al fuego, y caliente de lo hise veuer de una vez; el efecto q.e hiso fuè, que por dos oras estubo el enfermo quieto, despues se dispertò, y purgò cantidad de humores crasos, flematicos por mas de seis oras continuas hasta que del todo selè vajo la inchason y quedò sano al q.e yà estava a punto de morir. En falta de aseite puse el tuetano, y añadi la sal p.a haser el remedio [...] (LIBRO DE CIRUGÍA, 1725, p. 248).

Como se pode constatar, os procedimentos e os medicamentos indicados visavam à purga de humores para o pleno restabelecimento do enfermo, apontando para a adoção de princípios da teoria hipocrático-galênica. ${ }^{48} \mathrm{~A}$ menção de que, na falta do azeite usualmente empregado, o autor-compilador recorreu à gordura de tutano aponta para a realidade na qual viviam os missionários nas reduções e para a necessidade de adaptações e intervenções ágeis diante de certas enfermidades e ou da incidência de epidemias. Passagens como a que destacamos acima nos auxiliam, portanto, no entendimento das razões para a escrita e circulação de livros-síntese, tais como o Libro de Cirugía, que podiam ser transportados com facilidade, adequando-se à realidade que viviam tanto os religiosos, quanto os laicos encarregados do atendimento de doentes. ${ }^{49}$

\footnotetext{
${ }^{48}$ Sobre a teroria humoralista, ver mais em: Reis (2009) e Carneiro (1994).

${ }^{49}$ Há várias passagens que registram a atuação do autor-compilador do manuscrito como um homem voltado para as artes de curar - atuando como enfermeiro, cirurgião ou boticário - cujas experiências, observações e receitas conciliam sua condição de missionário, encarregado do conforto e salvação da alma, e de homem de ciência, empenhado em curar
} 
Neste capítulo, encontramos também informações sobre os medicamentos empregados para conter a "peste": [...] por duas rasones son de grande eficasia en la peste, fiebres malignas, achaques [...] q.e la masa dela sangre nò este afecto de pequenos orumos, y. q. ${ }^{\mathrm{e}}$ nò hasa embaraso en los pulmones. [...] (GRAVES y [doctos], 1725, p. 246). Não há, contudo, ao longo de suas páginas, qualquer menção ao uso de relíquias ou a orações para curar ou proteger os enfermos face à alta incidência de epidemias, e nem mesmo a uma possível punição divina aos indígenas reduzidos, o que parece se configurar em elemento que reforçaria, mais uma vez, a hipótese de que o autor-compliador do manuscrito não seja um religioso.

Ao referir-se aos tumores en geral, em um subcapítulo intitulado Del zaratán, palavra de origem árabe usada para descrever o tipo específico de câncer que se desenvolve nos seios das mulheres, encontramos a seguinte passagem:

[...] Cuando el cancro fuere en los Pechos, y nò se pudicien curar con remedio alguno, se estirparà cortandolo con navaja, sacando todo el tumor con sus raises, ò abriendo en cruz se descamarà, y con las manos se esprimirà para que salga toda la sangre melancolica q. ${ }^{e}$ estibieri cangregada en la circunferencia, luego se cauterisarà con sucebidad no produsca escara gruesa, y se aplicaran los polbos siguientes. [...] (LIBRO DE CIRUGÍA, 1725, p. 394).

Considerando que a assepsia surgiria somente no século XIX, há que se reconhecer que as intervenções cirúrgicas no século XVIII, além de arriscadas para os pacientes, estavam sujeitas à incidência de infecções. Acreditamos que, no caso relatado, a cauterização tenha sido empregada para atenuar os efeitos colaterais que se seguiam a este tipo de intervenção realizada no século XVIII. No entanto, o que chama a atenção no excerto é a informação de que o corte foi feito em formato de cruz, o que parece sugerir a invocação do auxílio divino para assegurar o êxito da operação. Já a indicação de espremer e de eliminar o sangue melancólico está em consonância com o pensamento hipocrático-galênico, evidenciando a apropriação das teorias médicas vigentes nas intervenções cirúrgicas realizadas nas reduções no Setecentos. ${ }^{50}$

os indígenas das enfermidades que sobre eles se abatiam. Já no $8^{\circ}$ capítulo, na página 349 , há a menção ao contato do autor-compilador com outro boticário responsável pela Botica do Colégio de Córdoba, o irmão jesuíta Henrique Peschke (1674-1729). Vale lembrar que Peschke conviveu como irmão jesuíta Pedro Montenegro e o padre Segismund Asperger no Colégio de Córdoba, o que poderia apontar para a possibilidade de que o manuscrito contenha relatos de experiências realizadas e de situações vividas por missionários jesuítas.

${ }^{50}$ Cabe ressaltar que foi apenas no século XIX que o procedimento de extração de câncer de mama - com a mastectomia radical - foi realizada por William Stewart Halsted (1852-1922), nos Estados Unidos. Considerando que não existiam, na 
No nono capítulo, intitulado Del Pulso, Orina y Crisis, o autor-compilador aborda as causas de baixa pressão arterial. A pulsação enfraquecida teria, segundo ele, relação com "[...] La demasiada evacuasion [...] el calor intenso, y aserrimo, la vigilia, la abstinencia de comida; el dolor grande; el temor, la tristesa, el movimiento demasiado del cuerpo, y el mucho coyto. [...]“ (LIBRO DE CIRUGÍA, 1725, p. 354). Esta passagem parece apontar para uma associação entre os problemas de pressão arterial e um comportamento moral [excesso de intercurso sexual], alvo de reiterada condenação dos missionários que atuavam nas reduções da região platina. Cabe, no entanto, ressaltar que a vinculação entre enfermidades e desaprovadas condutas morais não era estabelecida exclusivamente por religiosos, constituindo-se em aspecto destacado também por autores médicos laicos, tais como os referidos no Prólogo do Libro.

Neste capítulo, são também abordadas as crisis, percebidas como situações ápices de determinadas enfermidades, que encaminhariam o paciente para a melhora ou para a piora de seu quadro. De acordo com o Libro de Cirugía, existiam as "boas crises", nas quais o corpo sairia vencedor, e as "más crises", que consistiam no sucesso das enfermidades. Uma má crise poderia levar, até mesmo, ao óbito. Para que as crises fossem superadas, o manuscrito traz a indicação de seis condições - em consonância com a teoria humoralista - que deveriam considerar a enfermidade e a idade do enfermo, "e, assim os morbos agudos por excreções de vômitos, fezes, suor se terminam aos largos [...], fazem terminar a febre ardente no jovem pelo fluxo de sangue, e no velho termina, no mais das vezes, pelo fluxo do ventre" (LIBRO DE CIRUGÍA, 1725, p. 380).

A menção feita ao azeite extraído do "tapiti" pelos indígenas (LIBRO DE CIRUGÍA, 1725, p.318), dentre outras indicações, indicam a familiaridade do autor-compilador com certos saberes nativos adotados no tratamento de determinadas enfermidades. Sob esta perspectiva, as menções às experiências feitas para confirmar as propriedades curativas de plantas e animais, bem como o emprego de termos indígenas nos receituários parecem apontar para a síntese científica presente no Libro de Cirugía (1725). ${ }^{51}$ Chamou-nos a atenção, também, uma passagem do Libro que sugere a incorporação da farmacopeia nativa no tratamento de doenças na Europa: [...] La triaca aplicada se observó en la Peste de Mantua año de 1629, q.e matava [El carbunco], más combeniente son los medicamentos suabes q.e los acres [...] (LIBRO DE CIRUGÍA, 1725, p. 393).

\footnotetext{
Europa do Setecentos, métodos adequados para a remoção de cânceres de mama em seu último estágio, o relato de experiência de extração do zaratán - com um corte em forma de cruz, seguido de procedimentos humoralistas - que o Libro nos oferece parece apontar para a realização de experiências inovadoras no tratamento do câncer nas reduções da região platina.

${ }^{51}$ É plausível supor que o emprego das denominações de plantas e animais nas línguas nativas no Libro visasse tanto a facilidade de sua localização pelos indígenas das reduções, quanto sua correta utilização nas receitas indicadas nos tratamentos de enfermidades e nos procedimentos cirúrgicos.
} 
Já no sétimo capítulo da obra, Enfermedad de las mugeres, percebemos que as terapêuticas indicadas estão relacionadas com o mal de madre ${ }^{52}$ e visavam combater cólicas e dores pós-parto ou, então, fazer descer ou parar a menstruação. Para tanto, são indicadas diversas plantas e infusões, dentre as quais se encontram a canela, a matricaria (camomila), o asafran (açafrão), o ynojo (funcho) e o perejil (salsa). ${ }^{53}$ Estes ingredientes são mencionados em várias passagens do Libro, como neste preparado indicado para fazer descer a menstruação: "Es tambien buen remedio tomar cada mañana una dragma de preparado mesclado con un poco de miel, veuiendo inmediatamente media tasa de vino blanco, ó cosimiento de Artemisa" (LIBRO DE CIRUGÍA, 1725, p. 298). ${ }^{54}$ Para deter o fluxo de sangue após o parto, o autor-compilador do Libro recomenda o uso de Balsamo de Aguaraybay, uma planta nativa da América do Sul, que cresce no norte da Argentina, na região próxima de Córdoba, e possui propriedades purgantes. ${ }^{55}$ Sendo assim, o manuscrito nos oferece evidências tanto da circulação de plantas nativas da região platina entre colégios e reduções, quanto de sua utilização em receitas.

No Libro de Cirugía o autor não apresenta explicações detalhadas sobre a anatomia do corpo feminino, se detendo, principalmente, nas terapêuticas indicadas no tratamento de enfermidades próprias das mulheres. Entretanto, em algumas passagens ficam claros alguns conhecimentos sobre anatomia e sobre o funcionamento do corpo feminino, ${ }^{56}$ como no trecho em que o autor descreve as fases da vida fértil da mulher:

\footnotetext{
${ }^{52}$ A madre esteve sempre associada à reprodução, como podemos perceber nas próprias definições do termo. Rafael Bluteau, em seu Vocabulário português e latino, de 1721, define a madre como sendo a "parte em que se concebe e alimento o fruto" e, ainda, como "o útero das femeas, onde se desenvolve o feto antes de nascer" (BLUTEAU, 1721, p. 240). Já em 1752, os irmãos e cirurgiões Manuel José Affonso e José Francisco e Mello publicam o Novo método de partejar, recopilado dos mais famigerados sábios e doutores, no qual a madre aparece descrita como "uma entranha de substância membranosa, figurada como uma pêra com algumas cavidades em seu centro, de forma que o seu fundo fica superior e o orifício inferior corresponde à vagina" (AFFONSO; MELLO, 1752, p. 41).

${ }^{53}$ Vale lembrar que asafran, matricaria e canela eram largamente empregados em receitas para provocar los mestruos que constam em livros de medicina doméstica europeia. Para esta mesma finalidade, encontramos a indicação de plantas como sarsaparrilla, cardo corredor, apio, rais de perejil e lírio.

${ }^{54}$ É interessante observar que a maioria das infusões são feitas em vinho, fazendo-se uma diferenciação entre o uso do vinho branco e do vinho tinto.

${ }^{55}$ Cabe ressaltar que as propriedades emenagogas atribuídas ao "aguaribay" indicam que esta planta facilitava e aumenta o fluxo menstrual, divergindo da indicação que consta no Libro, pois o bálsamo é recomendado para deter o fluxo de sangue após o parto.

${ }^{56}$ É preciso considerar que nas reduções as mulheres prestes a dar à luz contavam com o apoio - e o conhecimento - de indígenas parteiras, encarregadas de atender gestantes e parturientes nas enfermarias e nos hospitais nelas instalados. É plausível supor que, as inúmeras situações de complicações de parto que o autor-compilador tenha presenciado ou, então, as informações que obteve de outros indígenas sobre o trabalho das parteiras, tenham favorecido a descrição de plantas nativas americanas com propriedades muito similares às que eram amplamente utilizadas na Europa, tais como a serpentária, a artemísia, o ciclâmen, a flor de violeta branca e a madressilva. Como pudemos constatar em estudo anterior (FLECK, 2015), tanto europeus, quanto indígenas conheciam uma infinidade de plantas e procedimentos que favoreciam o aborto, garantiam a continuidade da gravidez e, também, um bom parto. É muito provável que os boticários dos colégios e das reduções jesuíticas e, até mesmo aqueles que atuavam como enfermeiros ou médicos, conhecessem as propriedades abortivas das plantas nativas americanas e daquelas que passaram a ser cultivadas nos herbários mantidos pelos missionários. Vale lembrar, também, que livros de "medicina casera" circulavam amplamente na região platina, o que poderia explicar o conhecimento e o uso de preparados abortivos, bem como de procedimentos indicados, tanto para favorecer a expulsão dos fetos [em consequência de abortos] e para contornar dificuldades surgidas durante o parto, quanto para amenizar as dores no período pós-parto.
} 
Empiesa a vajar los mestruos à las mugeres de y fin del los 14, y les dura hasta los 40, ó 50. Seguen las complesiones, por que a unas les empiesa a bajar desde los 13 años, y a unas de 15, y lo mismo en el sesar, que a unas ya no les baja à los años, y a unas despues de los 50 los tienen. [...] los mestruos seguen los tiempos de la luna; a las muchachas les corre en el primer quarto, a las mosas en el $2^{\circ}$, y a las de más edad en el $3^{\circ}$, y alas viejas en el ultimo quarto de la luna [...] Y se há de saber que àlas mugeres quando les corre vir los mestruos, segun la costumbre que dura 3 días, mas ó menos, entonses viven sanas, castas, y son fecundas (LIBRO DE CIRUGÍA, 1725, p. 299).

Também encontramos menção a cesáreas, procedimento cirúrgico descrito detalhamente, mas não recomendado pelo autor, que se limita a afirmar que "rara ves tiene buen efecto" (LIBRO DE CIRUGÍA, 1725, p. 302), devendo ser empregadas somente quando fosse constatado que a mãe estava morta e que a criança ainda estivesse viva, a fim de que pudesse ser salva. Para controlar o sangramento após o parto, são indicados remédios e alimentos que não "derriten demasiado la sangre" (LIBRO DE CIRUGÍA, 1725, p. 306) e debilitassem ainda mais as forças da mulher, evidenciando a apropriação da medicina hipocrático-galênica pelo autor-compilador.

Como se pode observar este capítulo trata da menstruação, do parto e de doenças femininas de forma bastante detalhada para a época. Deve-se, no entanto, ressaltar que estes tratamentos, apesar de poderem ser do conhecimento dos jesuítas, não eram por eles executados, por razões fundadas na própria religião e moral do período, cabendo às mulheres indígenas o atendimento das parturientes e mesmo daquelas com males da madre. Considerando que o manuscrito, como anunciado no Prólogo, destinava-se ao pronto atendimento de enfermos, em especial, daqueles que viviam nas reduções da Companhia de Jesus, pode-se questionar as razões de as enfermidades femininas terem sido consideradas e incluídas em um suposto texto de autoria jesuítica. O detalhamento que caracteriza este capítulo parece reforçar a possibilidade que aventamos de que o manuscrito, ou, então, partes dele, como esta que se detém, especificamente, nas doenças próprias das mulheres, não tenha sido escrita por um religioso.

O capítulo De las Fiebres, y de su Diferencia trata sobre os diferentes tipos de febres, não descuidando de definir fiebre, que corresponderia, segundo o autor-compilador, a:

[...] calor no natural mudado en fuego [...] a diferencia del natural, que es el conservador de la vida, y el preternatural el destruidor de ella; 
mudado en fuego se dice a distincion de otro calor no natural, que no es bastante activo para producir fiebre, como es la ira, el exercisio \&, que produciendo calor preternatural no llega a ser febril (LIBRO DE CIRUGÍA, 1725, p. 317).

Existiriam, especificamente, três espécies de febres: as Eticas, as Putridas e as Efimeras. As Febres Eticas atingiam os membros sólidos e dividiam-se em três tipos, não mencionados especificamente pelo autor. As Putridas, que atingiam os humores, e as Efimeras, os espíritos, são tratadas mais a fundo e mereceram maior atenção quanto às suas variações e subespécies. As Putridas dividem-se em "colericas", "biliosas", "cotidianas", "flematicas", "melancolicas" e "sanguineas"; e, as Efimeras, em "causon", "tercianas", "quartanas" e "malignas".

Ao longo do capítulo, em consonância com as teorias médicas vigentes no Setecentos, diferentes terapias dietéticas são indicadas para cada tipo de febre. As Eticas, febres cujo principal efeito era o ressecamento de artérias e do coração - configurando-se em uma doença seca -, deveriam ser combatidas com tratamentos e alimentos úmidos, como "carnes de cangrejos", "caracoles", "tortugas" " "leche de baca", e, também, leite. As Pútridas, por sua vez, deveriam ser combatidas com uma dieta alimentar constituída por "seuada", "asucar", "caldos de pollo", "carne de carnero" ou "gallinas", e "lechugas". Também são indicadas plantas como "salvia", "romaza", "sem", "orosus", "esparrago" e "ybiamirri", empregadas tanto na alimentação como na composição de sudoríficos e vomitórios. Por fim, as dietas indicadas para as febres Efimeras são as mesmas empregadas no tratamento das febres Putridas, adicionando-se, apenas, a recomendação da ingestão de limões e laranjas.

Como pode-se observar, alguns alimentos são recomendados para o consumo, enquanto outros integram receitas indicadas no tratamento de enfermos febris. Dentre eles, destacamos o já mencionado leite. Seu consumo é fortemente recomendado para os enfermos que sofriam de febres Eticas, e é tido, inclusive, como "alimento, y remedio universal" (LIBRO DE CIRUGÍA, 1725, p. 349). Alguns alimentos também são empregados no combate das febres Efimeras, podendo ser utilizados para fazer compressas na cabeça dos enfermos. Este é o caso das cebolas, que podiam ser tanto ingeridas como aplicadas na pele dos Efimeros que apresentassem erupções em decorrência da subespécie mais letal das Efimeras, as Malignas. Enquanto certos tratamentos para as febres incluíam a ingestão de esterco, urina e animais vivos, como sapos, outros previam exclusivamente a ingestão de leite, desde que observadas algumas condições, como nesta indicação para o tratamento das febres Eticas: "Y el mejor tiempo de usarla será por las mañanas [...] hagan traer una baca mansa, gorda, negra, y nó vieja, ni mui joven [...] y ordeñen la leche en un baso que este metido dentro de otro baso lleno de agua bien caliente, para que assi con el calor que sale la beba el Enfermo (LIBRO DE CIRUGÍA, 1725, p. 349). 
Também neste capítulo, como nos demais, encontramos evidências da familiaridade do autor-compilador com os princípios da teoria dos humores e de sua aplicação, como nas passagens nas quais ele destaca que as febres resultantes dos humores frios eram mais demoradas do que aquelas que decorriam do calor; que as febres coléricas eram mais breves e menos agudas, e que as causadas pelo sangue eram menos agudas e breves em seus sintomas, embora demorassem mais para passar. O consumo e a utilização de certos alimentos e animais em receitas, por outro lado, parece apontar para uma combinação - ou adaptação - das receitas já consagradas e adotadas pela medicina caseira europeia com a flora e a fauna disponíveis nas regiões de atuação do autor-compilador ou de seus informantes religiosos ou laicos.

\section{Considerações Finais}

Considerando-se o estágio atual da investigação, não podemos afirmar que o manuscrito tenha tido um autor ou compilador jesuíta ou laico, o que, no entanto, não diminui sua relevância para a reconstituição dos saberes médicos da primeira metade do século XVIII na região platina. Apesar de o frontispício informar que o manuscrito foi redigido no ano de 1725 , acreditamos que sua primeira e segunda partes possam ter sido copiadas e reunidas em um período posterior, muito provavelmente, entre 1730 e 1740, portanto, nas duas décadas que antecederam a expulsão da Companhia dos domínios ibéricos.

A anotação "Aplicado a la libreria del convento de Catamarca", feita em grafia e formato típicos do século XVIII, nos leva a acreditar que o manuscrito, proveniente de outra biblioteca religiosa - muito provavelmente, jesuítica - ou, então, de doação feita por um médico laico, tenha integrado o acervo deste convento ainda no Setecentos. Mas, somente um exame mais apurado da história da biblioteca do convento de Catamarca, de seu acervo e da utilização que franciscanos e dominicanos fizeram do manuscrito possibilitará a confirmação ou refutação das hipóteses de Garzón Maceda, levantadas, muito provavelmente, a partir de informantes que forneceram tradições orais dos membros de ambas as ordens.

Trabalhos recentes têm apontado tanto para a premissa de que irmãos e padres da Companhia atuaram decisivamente na implantação de uma cultura científica nas terras de missão americanas, quanto para aquela que destaca a indiscutível contribuição dos indígenas para os conhecimentos que viriam a ser difundidos através da eficiente "rede de 
agentes da Companhia" encarregada de promover sua circulação entre os colégios jesuíticos da América e os da Europa (MILLONES FIGUEROA; LEDEZMA, 2005, p. 28).

Os capítulos do Libro de Cirugía, que analisamos neste artigo, parecem, efetivamente, apontar para a existência de uma rede de circulação de conhecimentos de medicina, cirurgia e botânica entre a América Platina e a Europa, fomentada, em grande medida, pela Companhia de Jesus, e que se evidencia tanto nos livros que integraram as bibliotecas de seus colégios, quanto nas obras de Matéria Médica que foram escritas por seus irmãos e padres durante o período de atuação como missionários na América. As muitas informações sobre plantas nativas e as referências diretas ou alusões a padres e irmãos jesuítas e a regiões de atuação da Companhia de Jesus (como a Chiquitania, por exemplo) que encontramos no Libro constituem-se em fortes indícios de sua circulação e utilização por boticários, enfermeiros e missionários da ordem.

A finalização da transcrição e da análise dos capítulos que compõem o Libro de Cirugía, e, em especial, do levantamento e da discussão das evidências de apropriações feitas de textos clássicos de Medicina e Farmácia, tanto dos europeus, quanto dos rio-platenses escritos no Setecentos, bem como das práticas terapêuticas e saberes nativos, possibilitará que lancemos novas hipóteses e compartilhemos novas informações sobre a procedência e a autoria deste manuscrito que se mantém anônimo e inédito até o momento.

\section{Referências}

ACERBI CREMADES, Norma. Los Jesuítas y la medicina de Córdoba desde 1599 a 1767. In: CONGRESO INTERNACIONAL JESUÍTAS 400 AÑOS EN CÓRDOBA, 4., 1999, Córdoba. Actas... Córdoba, 1999. p. 11-26.

AFFONSO, Manuel José; MELLO, José Francisco. Novo método de partejar, recopilado dos mais famigerados sábios e doutores. Lisboa: Miguel Rodrigues, 1752.

AMANTINO, Márcia; FLECK, Eliane Cristina Deckmann; ENGEMANN, Carlos (Org.). A Companhia de Jesus na América por seus colégios e fazendas: aproximações entre Brasil e Argentina (século XVIII). Rio de Janeiro: Garamond, 2015.

AMENTA, Sara Graciela. Instalación y primeros años de labor de la Orden Dominicana en San José del Monte de Lules, Tucumán después de la expulsión de los jesuitas. In: JORNADAS DE HISTORIA DE LA ORDEN DOMINICANA EN ARGENTINA, 2003, San Miguel de Tucumán. Actas... San Miguel de Tucumán, 2003. p. 85-96. 
ANAGNOSTOU, Sabine. Missionspharmazie: Konzepte, Praxis, Organization, wissenschaftliche Ausstrahlung. Stuttgart: Franz Steiner Verlag, 2011.

ANAGNOSTOU, Sabine; FECHNER, Fabian. Historia natural y farmácia misionera entre los jesuítas em el Paraguay. In: WILDE, Guillermo (Ed.). Saberes de la conversión: jesuítas, indígenas e impérios coloniales en las fronteras de la Cristandad. Buenos Aires: Editorial SB, 2011. p. 175-190.

ASÚA, Miguel de. La ciencia de Mayo: la cultura científica en el Río de la Plata, 1800-1820. Buenos Aires: Fondo de Cultura Económica, 2010.

ASÚA, Miguel de. Science in the Vanished Arcadia: knowledge of nature in the jesuit missions. Leiden: Brill, 2014.

BLUTEAU, Raphael. Supplemento ao vocabulario portuguez, e latino: parte II. Lisboa: Patriarcal Officina da Música, 1721.

CAÑIZARES ESGUERRA, Jorge. Como escribir la historia del Nuevo Mundo: historiografias, epistemologias e identidades en el mundo del Atlántico del siglo XVIII. México: Fondo de Cultura Económica, 2007.

CARNEIRO, Henrique Soares. Filtros, mezinhas e triacas: as drogas no mundo moderno. São Paulo: Xamã Editora, 1994.

CAROLINO, Luis Miguel. O paraíso do astrónomo: o céu empíreo segundo Cristoforo Borri (1583-1632). Clio: Série Revista de Pesquisa Histórica, Recife, v. 27, n. 1, p. 257-278, 2009.

CERTEAU, Michel de. A escrita da história. Rio de Janeiro: Forense Universitária, 1982.

CERTEAU, Michel de. A invenção do cotidiano. Petrópolis: Vozes, 1994.

CHARTIER, Roger; FAULHABER, Priscila; LOPES, José Sérgio Leite (Org.). Autoria e história cultural da ciência. Rio de Janeiro: Beco do Azougue, 2012.

DEL VALLE, Ivonne. Escribiendo desde los márgenes: colonialismo y jesuítas em el siglo XVIII. México: Siglo XXI, 2009.

DI LISCIA, María Silvia. Saberes, terapias y prácticas médicas en argentina (1750-1910). Madrid: Consejo Superior de Investiga Científicas Instituto de Historia, 2002.

ESPONERA CERDÁN, Alfonso. Los dominicos y la evangelización del Uruguay. Salamanca: Editorial San Esteban, 1992. 
FERREIRA, Marcela Aspell de Yanzi; PAGE, Carlos Alberto (Ed.). La biblioteca jesuítica de la Universidad Nacional de Córdoba. Córdoba: Universidade Nacional de Córdoba, 2000.

FLECK, Eliane Cristina Deckmann. Entre a caridade e a ciência: a prática missionária e científica da Companhia de Jesus (América platina, séculos XVII e XVIII). São Leopoldo: Oikos; Editora Unisinos, 2015.

FLECK, Eliane Cristina Deckmann; RODRIGUES, Luiz Fernando Medeiros; MARTINS, Maria Cristina Bohn. Enlaçar mundos: três jesuítas e suas trajetórias no Novo Mundo. São Leopoldo: Oikos; Editora Unisinos, 2014.

FRASCHINI, Alfredo Eduardo (Ed.). Index librorum Bibliothecae Collegii Maximi Cordubensis Societatis Iesu - Anno 1757: edición crítica filológica y bibliográfica. Buenos Aires: Universidad Nacional de Córdoba, 2003.

FURLONG, Guillermo. Medicos argentinos durante la dominación hispánica. Buenos Aires: Huarpes, 1947.

GARZÓN MACEDA, Félix. La Medicina en Córdoba: apuntes para su historia. Buenos Aires: Talleres Gráficos Rodrígues Giles, 1916.

GENETTE, Gerard. Palimpsestos: a literatura de segunda mão. Belo Horizonte: Faculdade de Letras, 2006.

GORZALCZANY, Marisa Andrea; OLMOS GAONA, Alejandro. La biblioteca jesuítica de Asunción. Buenos Aires: Os autores, 2006.

GUERRA, Francisco. Historia de la matéria médica hispano-americana y filipina en la epoca colonial. Madrid: Augado, 1974.

GUEVARA, José. Historia del Paraguay, Rio de la Plata y Tucumán. Anales de la Biblioteca de la República Argentina, 1908.

KRISTEVA, Julia. Semiótica. Madrid: Espiral; Ensayo, 1981.

LIBRO DE CIRUGÍA, 1725. Colección Manuscritos. Archivo Histórico de la Província Franciscana de la Santíssima Virgen del Rio de la Plata. Buenos Aires: Ediciones Castañeda, julho de 2014. 660 p. [versão digitalizada]

MARTÍN, Carmen Martín; VALVERDE, José Luis (ed.). La farmacia en la América colonial: el arte de preparar medicamentos. Granada: Servicio de Publicaciones de la Universidad de Granada, 1995. 
MILLONES FIGUEROA, Luis; LEDEZMA, Domingo (Ed.). El saber de los jesuitas, historias naturales y el Nuevo Mundo. Madrid: Iberoamericana, 2005.

MOYA, Silvano G. A. Benito. Bibliotecas y libros en la cultura universitaria de Córdoba durante los siglos XVII y XVIII. Información, Cultura y Sociedad, Ciudade Autónoma de Buenos Aires, n. 26, ene./jun. 2012.

O'NEILL, Charles; DOMINGUEZ, Joaquín-María. Diccionário histórico de la compañia de Jesús. Roma: Institutum Historicum SI; Madrid: Universidad de Comillas, 2001.

OBERMEIER, Franz. Ein neu entdecktes Guaranimanuskript zur Tradition der materia médica misionera im 18. Jahrhundert, Eine Sammelhandschrift zur Medizingeschichte des 18.Jahrhunderts aus dem La-Plata-Raum. Auskunft, Nordhausen [S. 1.], v. 37, n. 1, p. 111-139, 2017.

OTAZÚ MELGAREJO, Angélica. Contribución a la medicina natural: Pojha Ñaña, un manuscrito inédito en guaraní (Paraguay, S. XVIII). Corpus, Mendoza, v. 4, n. 2, p. 1-15, jul./dic. 2014.

PALAU y DULCET, Antonio. Manual del librero hispano-americano: bibliografía general española e hispanoamericana desde la invención de la imprenta hasta nuestros tiempos, con el valor comercial de los impresos descritos. 2. ed. Barcelona: Librería Anticuaria de A. Palau, 1948.

PARDAL, Ramón. Medicina aborigen americana. Sevilha: Ed. Renascimento, 1998.

PENNA, José. Prólogo. La história de la medicina en Córdoba. Revista de la Univ. Nacional de Córdoba, Córdoba, ano 4, n. 8, p. 1-42, oct. 1917. Disponível em: $<$ http://revistas.unc.edu.ar/index.php/REUNC/article/download/4447/6329>. Acesso em: 22 jan. 2018.

REIS, Ivoni Freitas. Um mapa da medicina antiga: entre a cura através dos contrários e a cura através dos semelhantes. Revista de Hitoria de la Medicina y Epistemología Médica, Buenos Aires, v. 1, p. 1-14, 2009.

VILLADA, Luis Martínez. Notas sobre la cultura cordobesa en la época colonial. Revista de la Universidad Nacional de Córdoba, Córdoba, v. 6, n. 9-10, p. 161-199, 1919.

Recebido em 31/01/2018

Aprovado em 24/05/2018 